\title{
Clostridial Infection After Open Fractures of the Lower Extremity - Report of Two Cases and Discussion of Pathomechanism and Treatment
}

\author{
MATHIAS TREMP ${ }^{1 *}$, CARLO M. ORANGES $^{1 *}$, MARTIN MAJEWSKI $^{2}$, DIRK J. SCHAEFER ${ }^{1}$, \\ DANIEL F. KALBERMATTEN ${ }^{1}$, CONSTANTINE BLOCH-INFANGER ${ }^{3}$ and PETER E. OCHSNER ${ }^{2}$ \\ ${ }^{1}$ Department of Plastic, Reconstructive, Aesthetic, and Hand Surgery, \\ Basel University Hospital, University of Basel, Basel, Switzerland; \\ ${ }^{2}$ Department of Orthopedic Surgery, Basel University Hospital, University of Basel, Basel, Switzerland; \\ ${ }^{3}$ Division of Infectious Diseases \& Hospital Epidemiology, \\ Basel University Hospital, University of Basel, Basel, Switzerland
}

\begin{abstract}
Background: Management of post-traumatic open fractures resulting from severe injuries of the lower extremity continues to challenge orthopedic and reconstructive surgeons. Moreover, post-traumatic osteoarticular infections due to Clostridium species are rare, with few reports in the literature. We describe possible pathomechanisms and propose treatment options for cases of delayed diagnosis of osteoarticular infections with Clostridium spp. Case Reports: Two patients sustained severe osteoarticular infection due to Clostridium spp. after open epi- and metaphyseal fractures of the lower extremity. In combination with radical debridement, ankle arthrodesis and long-term antibiotic treatment, satisfactory results were achieved after a followup of 18 months and 24 years. Conclusion: Clostridium species are difficult to identify, treatment is usually delayed and most patients have unfavourable outcomes.
\end{abstract}

Although Clostridium species can be found regularly in posttraumatic wounds, post-traumatic osteoarticular infection due to Clostridium is rare. Approximately 20 cases have been reported in patients with open fractures, located mainly in the diaphyseal area (1-4). Clostridium species are found most

This article is freely accessible online.

*These Authors contributed equally to this study.

Correspondence to: Dr. Mathias Tremp, MD, Basel University Hospital, Spitalstr. 21, 4031 Basel, Switzerland. Tel: +41 612652525, Fax: +41 612657301, e-mail: Mathias.Tremp@usb.ch

Key Words: Infection, osteomyelitis, Clostridium, trauma and injuries. often in fractures with severe environmental contamination of the wound during trauma (5).

Clostridium species are anaerobic or occasionally aerotolerant gram-positive rods, found in soil, feces, sewage and marine sediments (6). They have the ability to form endospores, mainly under anaerobic conditions. These spores display high resistance to physical and chemical influences and are not sensitive to antibiotics. In addition, several Clostridium species have the ability to produce numerous protein toxins, causing necrotizing tissue destruction (7). Thus, bone marrow necrosis or necrotic bone fragments may occur $(1,8)$.

The laboratory diagnosis of clostridial diseases depends on proper collection and handling of tissue samples (6). However, diagnosis is complicated by the fact that bone and joint infections due to Clostridium species are often polymicrobial (2). Although identification can be time-consuming, complete identification and testing of antimicrobial sensitivities have to be pursued. Species other than $C$. perfringens display a high variability in sensitivity testing, including to penicillin, cephalosporins, carbapenems and clindamycin (9).

Once the strain has been identified, aggressive surgical treatment is mandatory (10). When in doubt, temporary or definitive external fixation should be preferred over internal fixation to allow repeated lavage if necessary (2). Wound excision and lavage without extensive bone tissue resection nearly always fails (2), probably due to persistence of spores in surrounding tissue. All the infected tissue must be excised and any internal fixation hardware removed (2).

As a rule of thumb, Clostridium spp. complicating diaphyseal fractures cause extended bone loss due to necrosis. Reconstruction requires time-consuming segmental bone reconstruction, frequently combined with soft tissue restoration. In this report, we present two patients diagnosed with open malleolar dislocation fractures of the distal lower 

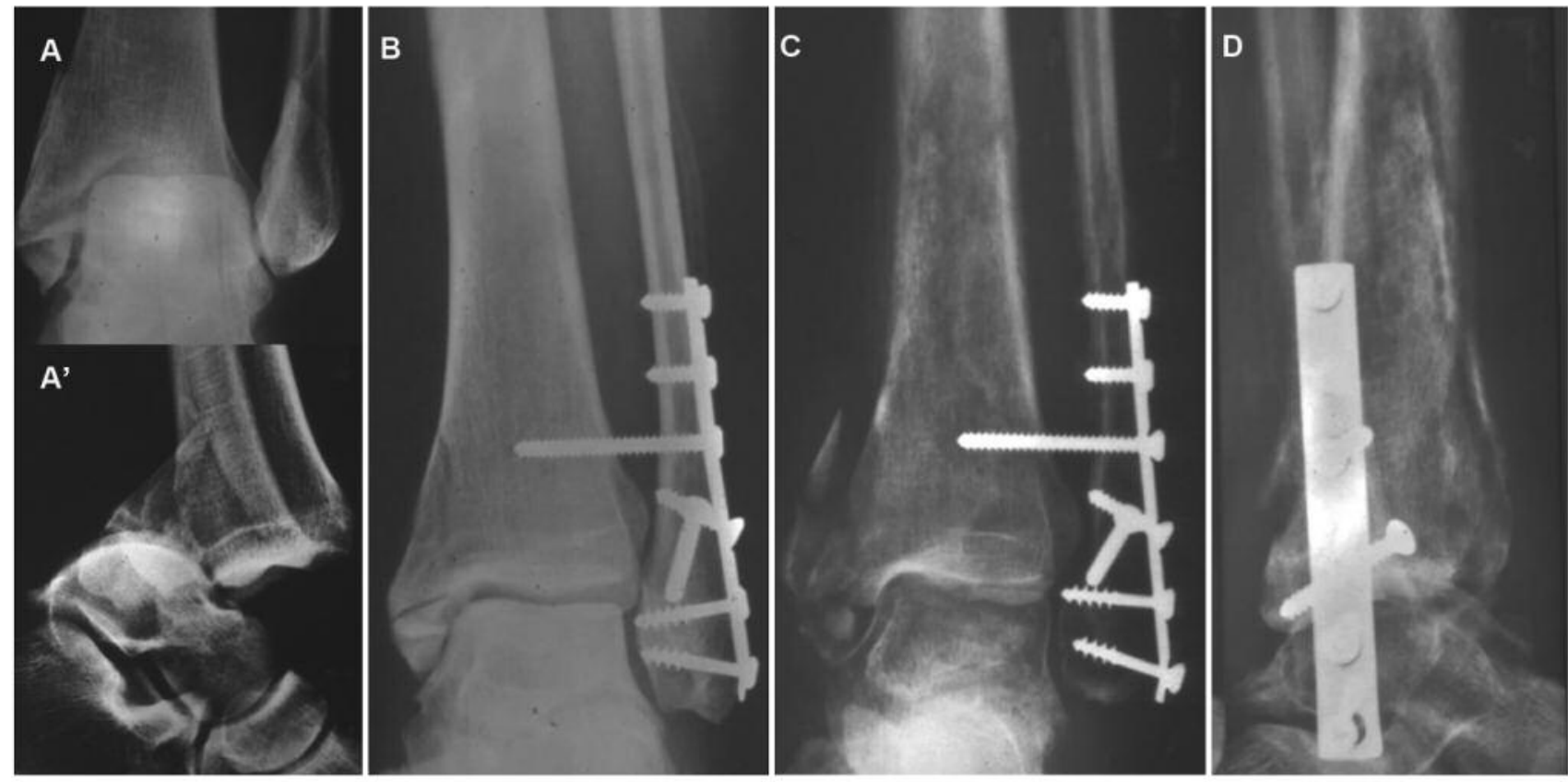

Figure 1. Case 1. A, A': Closed dislocation fracture. B: Immediate lateral osteosynthesis after reposition. C and D: Within 3 months, inner demarcation of the cancellous bone of the tibial pilon.

leg with subsequent osteoarticular infection due to Clostridium spp. It is the purpose of this article to analyse whether the extent of damage is similar to that in diaphyseal fractures. Furthermore, we describe possible pathomechanisms and propose treatment options for delayed diagnosis of osteoarticular infection with Clostridium spp.

\section{Case 1}

A 43-year-old non-smoking female farmer stumbled over a doorstep. Immediately afterwards she was admitted to the Emergency Department with a Gustilo grade 2 open, dislocated trimalleolar fracture of her lower left leg (Figure 1). Immediate reduction and internal fixation was performed. Due to fever and discharge of pus, revision was required on the sixth postoperative day. Bacteriology harvested at the sixth day showed clostridium species seven days later. The antibiotic therapy was completed according to resistance testing with metronidazole (Table I). Persistent pus production with open fistulae led to two further revisions, once presenting coagulase-negative Staphylococcus spp. Thereafter, the patient was referred to a tertiary centre 3 months after the accident, presenting with three persistent fistulae (Figure 1C). Debridement ended in removal of a large block of dead bone located in the centre of the epi/metaphyseal area and additional small sequestrae, leaving a bone defect of about $6 \mathrm{~cm}$ length (Figures 1C, 2A and B). Histological analysis showed non-vital bone elements in the resected block and chronic inflammation of the surrounding granulation tissue, containing mainly plasma cells and lymphocytes as a sign of chronic infection (Figure $2 \mathrm{C}$ and D). External fixation was applied, which was completed 2 weeks later together with an oblique tibial osteotomy for callus distraction and segmental transportation according to Ilizarov (11). The aim of this procedure was to compensate leg shortening and to allow fusion of the ankle joint (Figure 3 ). Further bacteriological tests remained negative. At 45 weeks later, the external fixation was removed and an orthosis applied. Subsequently, the patient was able to ambulate fully, weight bearing with minor pain. Thirteen years after the ankle fusion, the patient experienced massive arthrosis of the subtalar ankle joint, requiring a subtalar fusion and a supramalleolar correction osteotomy due to an equinus position of the foot (Figure 3C). After 24 years, the patient has only minimal pain and takes no analgesics. She is able to walk independently and is satisfied with the final result, despite osteoarthrosis of the opposite hip.

\section{Case 2}

A 58-year-old woman fell into a 2-meter deep cesspool, sustaining a bimalleolar luxation fracture and type II soft 

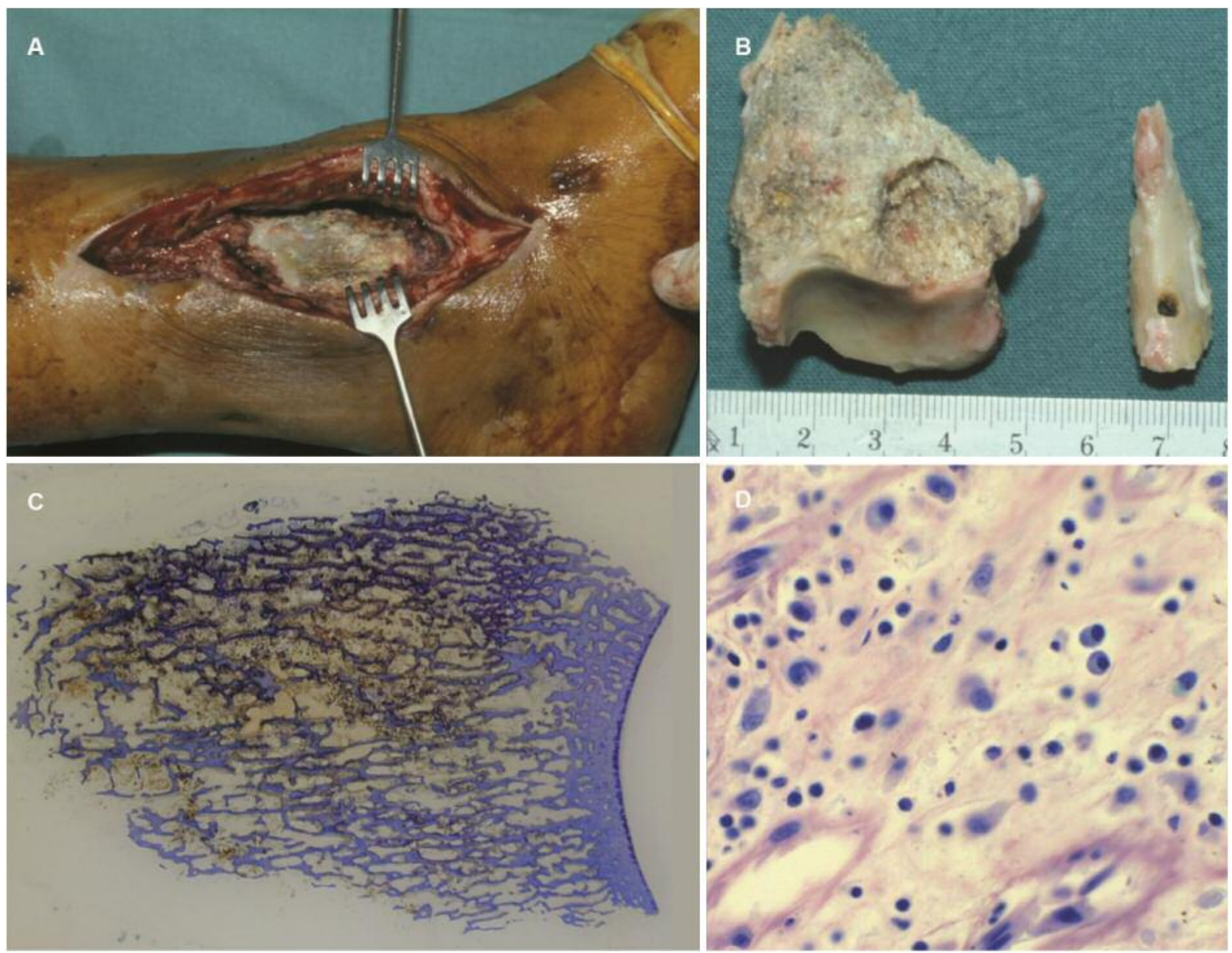

Figure 2. Case 1. A: Medial revision presents a demarcation of the central tibial pilon. B: Resected parts of the pilon and the fibula. C: Undecalcified longitudinal section of the pilon, coloured with toluidine blue. An intact joint surface and a demarcated irregular cancellous bone surface are visible. D: Soft tissues of the area under high magnification show chronic infection with plasma cells and lymphocytes (10x magnification).

Table I. Chronology and therapy of case 1.

\begin{tabular}{|c|c|c|c|c|c|}
\hline $\begin{array}{l}\text { Time after accident } \\
\text { (weeks) }\end{array}$ & Surgery & Bacteriology & $\begin{array}{l}\text { Antibiotic } \\
\text { therapy }\end{array}$ & $\begin{array}{c}\text { Duration } \\
\text { (weeks) }\end{array}$ & $\begin{array}{l}\mathrm{CRP} \\
(\mathrm{mg} / \mathrm{l})\end{array}$ \\
\hline 0 & Open reduction and internal fixation & & Amoxicillin/clavulanic acid & 1 & $<5$ \\
\hline \multirow[t]{3}{*}{1} & Revision & a) Negative & Amoxicillin/clavulanic acid & 4 & $<5$ \\
\hline & & b) Clostridium spp & Garamycin & 3 & \\
\hline & & Metronidazole & 4 & & \\
\hline 3 & Revision, irrigation, drainage & Negative & & & $<5$ \\
\hline 8 & Revision & CNS & Clindamycin & 1 & $<5$ \\
\hline \multirow[t]{3}{*}{13} & Removal of sequestrae and metal, & Negative & Amoxicillin/clavulanic acid & 1.5 & $<5$ \\
\hline & external fixation & & Clindamycin & 6 & \\
\hline & & & Rifampicin & 4 & \\
\hline 15 & $\begin{array}{l}\text { Tibial osteotomy and segmental } \\
\text { transportation for later ankle fusion }\end{array}$ & & & & \\
\hline 45 & Removal external fixation & & & & 66 \\
\hline
\end{tabular}

CNS: Coagulase-negative Staphylococcus spp.; CRP: C-reactive protein. 

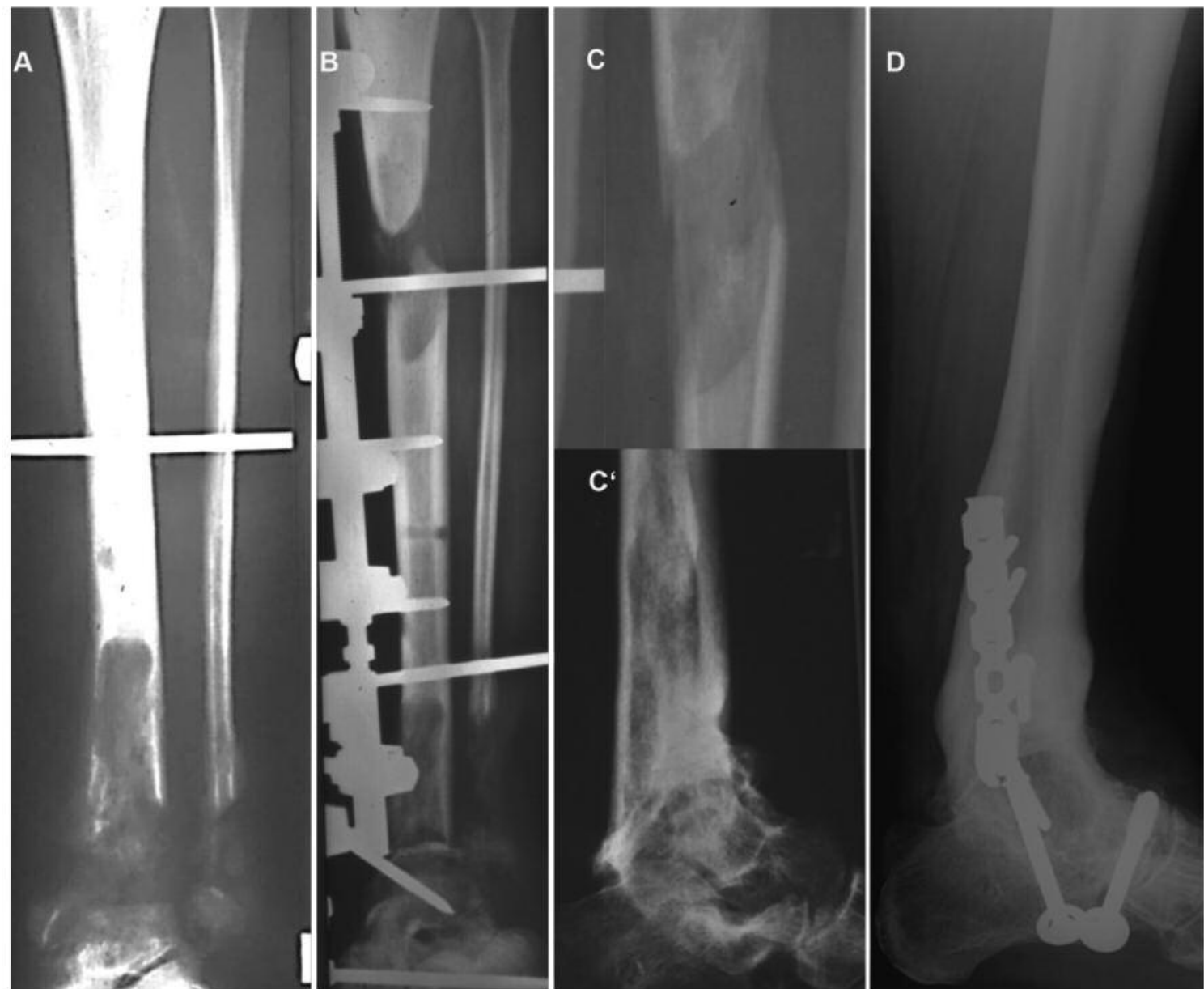

Figure 3. Case 1. A: Bone loss of the pilon of about $6 \mathrm{~cm}$ in length. B: Appearance at the end of callus distraction. C, C': At 45 weeks later, the external fixation was removed and an orthosis applied. D: Thirteen years later subtalar arthrodesis combined with correction osteotomy of the distal tibia to overcome equinus position.

tissue damage according to Gustilo (Figure 4A) (12). The patient was a non-smoker and diagnosed with type II diabetes. At 105 min after the accident, she was referred first to the regional hospital and then $5 \mathrm{~h}$ later to a secondary referral centre. There, she was given tetanus immunization and $1.5 \mathrm{mg}$ cefuroxim thrice daily was administered parenterally for 5 days. Seven hours after the accident, a thorough debridement, reduction of the dislocation and stabilization with an external fixation was performed in the operating theatre. Open reduction and internal fixation were performed 4 days later (Figure 4B). Due to wound tension and swelling, negative pressure treatment (NPT) was applied laterally. After seven changes of the NPT, a smear from the lateral wound obtained 17 days after the accident showed Clostridium butyricum 7 days after cultivation. Twenty-five days later, removal of all the osteosynthesis and external fixation was necessary due to formation of an abscess (Table
II). Magnetic resonance imaging (MRI) and computed tomographic scan showed inflammation of the distal tibia and osteopenia. To cover the soft-tissue defect, a free gracilis flap was performed using the secret scar technique (Figure 5) $(13,14)$. The external fixation was removed 11 weeks later and a nail-implantation inserted. Revision was then required to drain an abscess and to remove the nail. Scintigraphy and MRI after 5 months suggested the presence of sequestrating osteomyelitis of the tibial pilon, although the patient had no fever, redness or swelling around the ankle joint (Figure 4C). The patient was referred to a university hospital. The gracilis flap was elevated laterally and the bone exposed. A brownish-porous substance including cancellous sequestra was found and curetted out of the tibia (Figure 6A). The biopsies still contained the same bacteria (Table II). The histology showed necrotizing osteomyelitis and haematoid pigment with infiltration of bacteria. The 

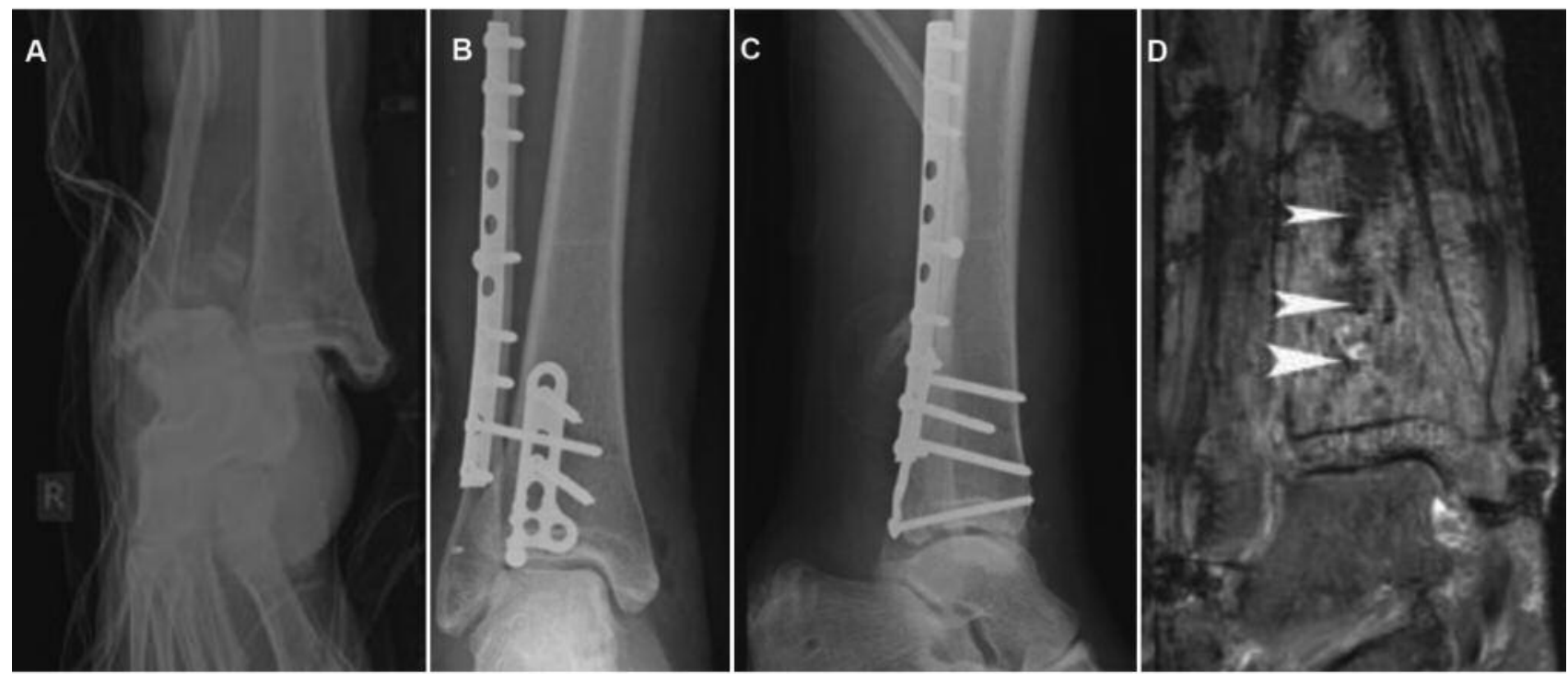

Figure 4. Case 2. A: Grade 2 open dislocation fracture helped with primary debridement and external fixation. B and C: Internal fixation 4 days later. D: Magnetic resonance imaging after 5 months with arrowheads showing strong evidence of sequestrae in the tibial pilon.

Table II. Chronology and therapy of case 2.

\begin{tabular}{|c|c|c|c|c|c|}
\hline $\begin{array}{l}\text { Time after accident } \\
\text { (weeks) }\end{array}$ & Surgery & Bacteria & $\begin{array}{l}\text { Antibiotic } \\
\text { therapy }\end{array}$ & $\begin{array}{l}\text { Duration } \\
\text { (weeks) }\end{array}$ & $\begin{array}{l}\mathrm{CRP} \\
(\mathrm{mg} / \mathrm{l})\end{array}$ \\
\hline 0 & External fixation & None & Cefuroxim & 1 & $<5$ \\
\hline 0.5 & $\begin{array}{c}\text { Open reduction and internal } \\
\text { fixation, NPT }\end{array}$ & & & & \\
\hline 2.5 & NPT change & Clostridium butyricum & Amoxicillin/clavulanic & 12 & 40.7 \\
\hline 4 & $\begin{array}{l}\text { Removal osteosynthesis, } \\
\text { external fixation }\end{array}$ & C. butyricum & Clostridium sp. & & 29.4 \\
\hline & & Robinsoniella peoriensis & & & 11.1 \\
\hline 6 & Gracilis flap & $\begin{array}{c}\text { C. butyricum } \\
\text { Propionibacterium acnes } \\
\text { Robinsoniella peoriensis }\end{array}$ & Metronidazole & 1 & \\
\hline 15 & Removal external fixation & None & $\begin{array}{c}\text { Daptomycin/ertapenem } \\
\text { Amoxicillin/clavulanic acid }\end{array}$ & Perioperative & \\
\hline 2.5 & 1 & & & & \\
\hline 19 & Revision abscess & C. butyricum & Piperacillin/tazobactam & 1 & 5.1 \\
\hline 21 & Metal removal & None & Amoxicillin/clavulanic acid & 6 & 20.9 \\
\hline 26 & $\begin{array}{l}\text { Ankle fusion with } \\
\text { external fixation }\end{array}$ & $\begin{array}{c}\text { C. butyricum } \\
\text { C. celerescens, } R \text {. peoriensis }\end{array}$ & $\begin{array}{l}\text { Imipenem } \\
\text { Penicillin }\end{array}$ & $\begin{array}{l}0.5 \\
0.5\end{array}$ & 6.9 \\
\hline & & & Metronidazole & 12 & 2.4 \\
\hline 48 & Removal external fixation & & & & \\
\hline
\end{tabular}

NPT: Negative pressure treatment; CRP: C-reactive protein.

ankle was fused with external fixation using the fibula as a bone bridge (Figure 6B). According to resistance testing, oral treatment with $500 \mathrm{mg}$ metronidazole thrice daily was prescribed for a total of 12 weeks. The external fixation was removed 22 weeks later (Figure 6C). At the follow-up after
18 months, there were no signs of infection, with stable softtissue coverage. The patient was full weight-bearing without pain, and radiography showed bony union. Importantly, it was possible to replace the aircast walking boot with an adapted shoe. 

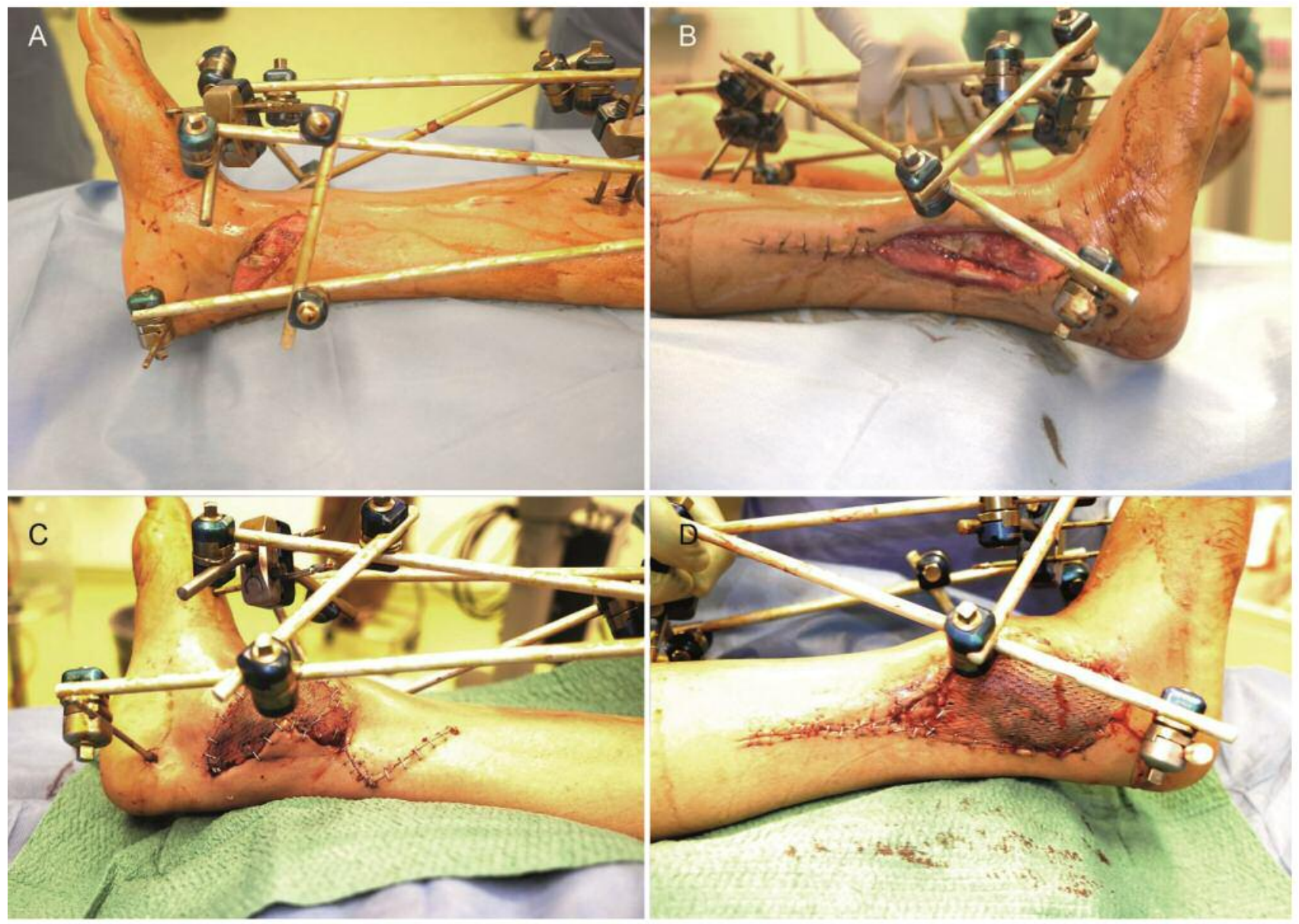

Figure 5. Case 2. Soft-tissue closure after 6 weeks. Appearance before (A and B) and after (C and D) the operation. The gracilis muscle was tunnelled medially to laterally.
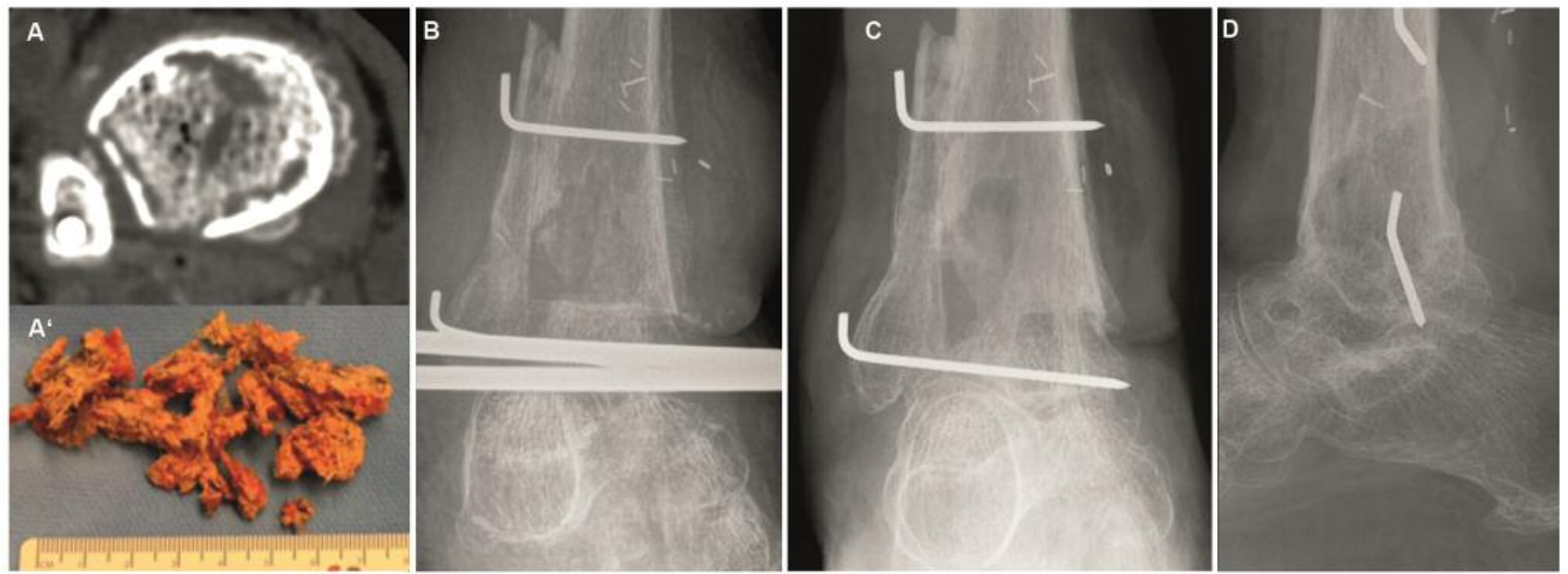

Figure 6. Case 2. A, A': Preoperative computed tomographic-scan through the tibial pilon area presenting a demarcation of the cancellous bone, which then was resected. B: Ankle fusion with external fixation. C and D: Fixation was removed 22 weeks later, when the fusion was solid enough. 


\section{Discussion}

Our two cases are remarkable and show that Clostridium spp. can cause severe osteomyelitis after open epi- and metaphyseal tibial fractures. In both cases, local bone necrosis in the pilon tibial was the common finding. Whereas the epiphyseal bone necrosis was attributed to the open dislocation leading to a possible devascularisation (4), the extension into the metaphyseal area could not be explained by this mechanism as there are hardly vascular connections between the tibial meta- and epiphyses (15). In a recent study by Blanke et al., clinical manifestations and risk factors were identified for the development of post-traumatic osteonecrosis (PON) of the distal tibia. Therein, all identified risk factors were associated with heavy fracture mechanisms, leading most likely to serious devascularisation of at least parts of the distal tibial epiphysis (4). Seventy-five percent of patients with PON sustained fractures through a high-energy trauma mechanism, and the combination of tibiotalar dislocation, severe soft-tissue damage and type Weber C-fracture of lateral malleolus was associated with PON in all of the cases. Interestingly, late joint reduction, postoperative infection or bimalleolar fracture were not found at a higher proportion in patients with PON (4).

The patients were treated with a combination of radical and serial debridement of the bone, identification of the bacteria, antibiotic sensitivity testing, ankle arthrodesis and adequate long-term antibiotic treatment. Satisfactory long-term results, consisting of bony union, recovery of ambulatory ability and stability of scars were achieved. Therefore, a multidisciplinary team approach is recommended.

The genus Clostridium comprises more than 200 species and subspecies (http://www.dsmz.de). Different species of Clostridium are known to cause necrotizing tissue infection. Typical examples are $C$. perfringens causing gas gangrene and $C$. sordelli causing gynecological infections. The reasons for the potentially vast necrosis caused by infections with different types of Clostridium are several types of extracellular toxins with the potential to cause intravascular activation of platelets with consecutive formation of occlusive thrombi, destruction of cell membranes causing cell lysis, modulation of inflammatory response and modulation of signaling molecules that control the cell cycle, apoptosis and gene transcription (9). The intraoperative findings in our two cases with extensive bone necrosis indicate that the Clostridium species involved had the ability to form some type of toxin, causing tissue death.

Post-traumatic osteoarticular infections due to Clostridium species have rarely been reported in the literature. Open fracture management is guided by well-defined steps aimed at reducing the risk of suppurative infections (16). Furthermore, hyperbaric oxygen therapy may contribute to the management of anaerobic bone infections when used in combination with surgery and antibiotics (2).
In addition to the application of Advanced Trauma Life Support, tetanus management principles are critical (16). Nevertheless, the issues of appropriate antibiotic prophylaxis, ideal timing for operative debridement, and appropriate timing of wound closure after debridement are in constant evolution (16). Prompt administration of antibiotics, based on the grade of injury, can be viewed more as treatment for presumptive infection or contamination, rather than simply prophylaxis (17). Furthermore, it has been suggested that delay in admission to the definitive treating trauma center of more than 2 hours after injury was associated with a 5.4-fold increased risk of developing an infection (18).

Our report confirms that the identification of Clostridium species in specimens from an osteoarticular infection requires extremely extensive and aggressive surgical resection (2). Often, the implantation of fixation hardware on an emergency basis is followed initially by skin necrosis, delayed wound healing, and a seropurulent discharge (2). Other possible reasons for the persistence of infection are an inadequate initial antimicrobial drug regimen, poor diffusion of antibiotic treatment due to the presence of necrotic tissue and the formation of persisting endospores (19). It has been postulated that if a fracture is at risk of contamination with Clostridium, such as after farm-related injuries, penicillin should be added to the antibiotic regimen (20). Thus, the administration of cephalosporin in the case of patient 2 was potentially insufficient due to the severe contamination of the injury with liquid manure. Continuing the prophylactic antibiotics for longer than $48 \mathrm{~h}$ is not recommended, as this strategy may put selective pressure on the bacteria, thereby inducing endospore production (2). Despite a multitude of studies, there is no clear evidence of the superiority of a multiple-dose regimen compared with a single-dose one (2124). However, patients having three or four peri-operative doses appear to have the lowest risk for re-operation at 10 years (21).

Ibnoulkhatib and co-workers retrospectively reviewed 12 patients with Clostridum spp. bone and/or joint infections complicating compound limb fractures with soil contamination and extensive soft-tissue damage. The median time to identification of Clostridium species was 14.5 days. Outcomes were assessed after a follow-up of at least 18 months following identification of the organism. In all 12 patients, the immediate outcome was unfavourable, requiring early reoperation (2).

\section{Conclusion}

Osteoarticular infections due to Clostridium spp. are rare but serious and require prompt and extensive treatment. Adequate antibiotic prophylaxis, early identification of disease-causing bacteria, antibiotic sensitivity testing, aggressive surgical 
treatment and possibly anatoxin-base anti-tetanus vaccine may prevent colonization and chronic infection.

\section{Conflicts of Interest}

The Authors declare that they have no conflicts of interest. None of the Authors has a financial interest in any of the products, devices, or drugs mentioned in this article.

\section{Authors' Contributions}

Study design: Mathias Tremp, Carlo M. Oranges, Dirk J. Schaefer, Daniel F. Kalbermatten, Peter E. Ochsner; Data acquisition and collection: Mathias Tremp, Carlo M. Oranges, Daniel F. Kalbermatten, Peter E. Ochsner; Manuscript drafting: Mathias Tremp, Carlo M. Oranges; Critical revision: all Authors. Final approval: all Authors.

\section{References}

1 Carlier JP, Manich M, Loiez C, Migaud H and Courcol RJ: First isolation of Clostridium amygdalinum from a patient with chronic osteitis. J Clin Microbiol 44: 3842-3844, 2006. PMID: 17021125. DOI: $10.1128 / \mathrm{JCM} .01200-06$

2 Ibnoulkhatib A, Lacroix J, Moine A, Archambaud M, Bonnet E, Laffosse JM and Crioac GSO: Post-traumatic bone and/or joint limb infections due to Clostridium spp. Orthopaed Traumatol Surg Res 98: 696-705, 2012. PMID: 22951052. DOI: 10.1016/j.otsr.2012.03.019

3 Taylor SM, Wolfe CR, Dixon TC, Ruch DS and Cox GM: Wound botulism complicating internal fixation of a complex radial fracture. J Clin Microbiol 48: 650-653, 2010. PMID: 20007390. DOI: 10.1128/JCM.01258-09

4 Blanke F, Loew S, Ferrat P, Valderrabano V, Ochsner PE and Majewski M: Osteonecrosis of distal tibia in open dislocation fractures of the ankle. Injury 45: 1659-1663, 2014. PMID: 25087074. DOI: $10.1016 /$ j.injury.2014.06.023

5 Brook I and Frazier EH: Anaerobic osteomyelitis and arthritis in a military hospital: a 10-year experience. Am J Med 94: 21-28, 1993. PMID: 8420297. DOI: 10.1016/0002-9343(93)90115-6

6 Versalovic J, Carroll KC, Funke G, Jorgensen JH, Landry ML and Warnock DW: Manual of Clinical Microbiology, ASM Press, Washington, DC, USA, 2011.

7 Mandell GL, Bennett JE and Dolin R: Principles and Practice of Infectious Diseases, sixth edition. Churchill Livingstone, Elsevier, Philadelphia, PA, USA, 2004.

8 Lazarescu C, Kimmoun A, Blatt A, Bastien C and Levy B: Clostridium perfringens gangrenous cystitis with septic shock and bone marrow necrosis. Intensive Care Med 38: 1906-1907, 2012. PMID: 22797355. DOI: 10.1007/s00134-012-2647-4

9 Hecht DW: Anaerobes: Antibiotic resistance, clinical significance, and the role of susceptibility testing. Anaerobe 12: 115-121, 2006. PMID: 16765857. DOI: 10.1016/j.anaerobe.2005.10.004

10 Hall BB, Rosenblatt JE and Fitzgerald RH, Jr: Anaerobic septic arthritis and osteomyelitis. Orthoped Clinics N Am 15: 505-516, 1984. PMID: 6472831.

11 Ilizarov GA, Lediaev VI and Shitin VP: The course of compact bone reparative regeneration in distraction osteosynthesis under different conditions of bone fragment fixation (experimental study). Eksp Khir Anesteziol 14: 3-12, 1969. PMID: 5385792.
12 Gustilo RB and Anderson JT: Prevention of infection in the treatment of one thousand and twenty-five open fractures of long bones: retrospective and prospective analyses. J Bone Joint Surg Am 58: 453-458, 1976. PMID: 773941.

13 Tremp M, Wettstein R, Raffoul W, Schaefer DJ and Kalbermatten DF: Secret scar-free gracilis flap. J Reconstr Microsurg 28: 341344, 2012. PMID: 22588799. DOI: 10.1055/s-0032-1313765

14 Oranges CM, Tremp M, Wang W, Madduri S, DI Summa PG, Wettstein R, Schaefer DJ and Kalbermatten DF: Patient height, weight, BMI and age as predictors of gracilis muscle free-flap mass in lower extremity reconstruction. In Vivo 32(3): 591-595. 2018. PMID: 29695565. DOI: 10.21873/invivo.11280

15 Menck J, Bertram C and Lierse W: Sectorial angioarchitecture of the human tibia. Acta Anat 143: 67-73, 1992. PMID: 1585791. DOI: $10.1159 / 000147230$

16 O'Brien BS, McNally MP and Duncan JE: Controversies surrounding quality measurement in colon and rectal surgery. Clinics Colon Rectal Surg 27: 26-31, 2014. PMID: 24587701. DOI: $10.1055 / \mathrm{s}-0034-1366916$

17 Lawrence RM, Hoeprich PD, Huston AC, Benson DR and Riggins RS: Quantitative microbiology of traumatic orthopedic wounds. J Clin Microbiol 8: 673-675, 1978. PMID: 744799.

18 Pollak AN, Jones AL, Castillo RC, Bosse MJ, MacKenzie EJ and Group LS: The relationship between time to surgical debridement and incidence of infection after open high-energy lower extremity trauma. J Bone Joint Surg Am 92: 7-15, 2010. PMID: 20048090. DOI: 10.2106/JBJS.H.00984

19 Levy PY, Fournier PE, Lotte L, Million M, Brouqui P and Raoult D: Clostridium tetani osteitis without tetanus. Emerging Infect Dis 20: 1571-1573, 2014. PMID: 25152389. DOI: 10.3201/eid2009.131579

20 Cross WW, 3rd and Swiontkowski MF: Treatment principles in the management of open fractures. Ind J Orthopaed 42: 377-386, 2008. PMID: 19753224. DOI: 10.4103/0019-5413.43373

21 Engesaeter LB, Lie SA, Espehaug B, Furnes O, Vollset SE and Havelin LI: Antibiotic prophylaxis in total hip arthroplasty: effects of antibiotic prophylaxis systemically and in bone cement on the revision rate of 22,170 primary hip replacements followed 0-14 years in the Norwegian Arthroplasty Register. Acta Orthopaed Scand 74: 644-651, 2003. PMID: 14763692. DOI: 10.1080/00016470310018135

22 Wymenga A, van Horn J, Theeuwes A, Muytjens H and Sloff T: Cefuroxime for prevention of postoperative coxitis. One versus three doses tested in a randomized multicenter study of 2,651 arthroplasties. Acta Orthop Scand 63: 19-24, 1992. PMID: 1738963. DOI: $10.3109 / 17453679209154842$

23 Lidgren L: Joint prosthetic infections: A success story. Acta Orthop Scand 72: 553-556, 2001. PMID: 19995311. DOI: 10.3109/17453670903487016

24 Walenkamp GHIM: Prevention of infection in orthopaedic surgery. In: European Instructional Course Lectures. Thorngren K-G, Soucacos P N, Horan F and Scott J (eds.). The British Editorial Society of Bone and Joint Surgery, London 5: 5-17, 2001.

Received October 6, 2019

Revised October 20, 2019

Accepted October 22, 2019 